\title{
Flux measurements and maintenance energy for carbon dioxide utilization by Methanococcus maripaludis
}

\author{
Nishu Goyal ${ }^{1}$, Mrutyunjay Padhiary $^{2}$, Iftekhar A. Karimi ${ }^{*}$ and Zhi Zhou ${ }^{2,3^{*}}$
}

\begin{abstract}
Background: The rapidly growing mesophilic methanogen Methanococcus maripaludis $\mathrm{S} 2$ has a unique ability to consume both $\mathrm{CO}_{2}$ and $\mathrm{N}_{2}$, the main components of a flue gas, and produce methane with $\mathrm{H}_{2}$ as the electron donor. The existing literature lacks experimental measurements of $\mathrm{CO}_{2}$ and $\mathrm{H}_{2}$ uptake rates and $\mathrm{CH}_{4}$ production rates on $\mathrm{M}$. maripaludis. Furthermore, it lacks estimates of maintenance energies for use with genome-scale models. In this paper, we performed batch culture experiments on M. maripaludis $\mathrm{S} 2$ using $\mathrm{CO}_{2}$ as the sole carbon substrate to quantify three key extracellular fluxes $\left(\mathrm{CO}_{2}, \mathrm{H}_{2}\right.$, and $\left.\mathrm{CH}_{4}\right)$ along with specific growth rates. For precise computation of these fluxes from experimental measurements, we developed a systematic process simulation approach. Then, using an existing genome-scale model, we proposed an optimization procedure to estimate maintenance energy parameters: growth associated maintenance (GAM) and non-growth associated maintenance (NGAM).

Results: The measured extracellular fluxes for M. maripaludis showed excellent agreement with in silico predictions from a validated genome-scale model (iMM518) for NGAM $=7.836 \mathrm{mmol} / \mathrm{gDCW} / \mathrm{h}$ and GAM $=27.14 \mathrm{mmol} / \mathrm{gDCW}$. M. maripaludis achieved a $\mathrm{CO}_{2}$ to $\mathrm{CH}_{4}$ conversion yield of 70-95\% and a growth yield of $3.549 \pm 0.149 \mathrm{~g} \mathrm{DCW} / \mathrm{mol}$ $\mathrm{CH}_{4}$ during the exponential phase. The ATP gain of $0.35 \mathrm{~mol}$ ATP/molCH $\mathrm{H}_{4}$ for M. maripaludis, computed using NGAM, is in the acceptable range of $0.3-0.7 \mathrm{~mol} \mathrm{ATP} / \mathrm{molCH}_{4}$ reported for methanogens. Interestingly, the uptake distribution of amino acids, quantified using iMM518, confirmed alanine to be the most preferred amino acids for growth and methanogenesis.

Conclusions: This is the first study to report experimental gas consumption and production rates for the growth of M. maripaludis on $\mathrm{CO}_{2}$ and $\mathrm{H}_{2}$ in minimal media. A systematic process simulation and optimization procedure was successfully developed to precisely quantify extracellular fluxes along with cell growth and maintenance energy parameters. Our growth yields, ATP gain, and energy parameters fall within acceptable ranges known in the literature for hydrogenotrophic methanogens.
\end{abstract}

Keywords: M. maripaludis, Hydrogenotrophic methanogen, $\mathrm{CO}_{2}$ utilization, Maintenance energy, Extracellular fluxes

\section{Background}

In light of rapidly growing $\mathrm{CO}_{2}$ emissions, capture and conversion of $\mathrm{CO}_{2}$ to useful fuels and chemicals is

\footnotetext{
*Correspondence: cheiak@nus.edu.sg; zhizhou@purdue.edu

${ }^{1}$ Department of Chemical and Biomolecular Engineering, National University of Singapore, 4 Engineering Drive 4, Singapore 117585 , Singapore

${ }^{3}$ Division of Environmental and Ecological Engineering and School of Civil Engineering, Purdue University, 550 Stadium Mall Drive, West Lafayette, IN 47907, USA

Full list of author information is available at the end of the article
}

becoming increasingly important. Since the redox potential of converting $\mathrm{CO}_{2}$ to $\mathrm{CH}_{4}$ is high $(-240 \mathrm{mV})$, a synthetic chemical conversion requires expensive catalysts, harsh reaction conditions, and high energy [1]. In contrast, coenzymes in methanogens can act as biocatalysts and reduce the activation energy for higher conversion efficiency under benign conditions. Thus, a microbial conversion process not only captures $\mathrm{CO}_{2}$ from flue gas emissions, but also makes a promising carbon-neutral biofuel, such as $\mathrm{CH}_{4}$. 
The ecological role of methanogens to remove $\mathrm{CO}_{2}$ from the environment via methanogenesis has been widely studied $[2,3]$. Among methanogens, M. maripaludis $\mathrm{S} 2$ is a fully sequenced, rapidly growing, hydrogenotrophic methanogen, that has the capability to consume major components $\left(\mathrm{CO}_{2}\right.$ and $\left.\mathrm{N}_{2}\right)$ of a flue gas $[4,5]$. M. maripaludis converts $\mathrm{CO}_{2}$ to $\mathrm{CH}_{4}$ in the presence of electron donors such as $\mathrm{H}_{2}$ [4] or formate [6], and also possesses a unique ability to fix $\mathrm{N}_{2}$ to ammonia [5, $7,8]$. Although several studies have characterized and engineered the metabolic pathways in M. maripaludis, quantitative measurements on $\mathrm{CO}_{2}$ utilization and $\mathrm{CH}_{4}$ production are absent in the literature. Furthermore, no study to date has quantified the distribution of carbon flux between biomass synthesis and methanogenesis in this microorganism.

Genome-scale models are very useful for quantifying extracellular and intracellular fluxes, analyzing cultivation data, designing media and processes, and engineering microbial strains for enhanced production $[9,10]$. However, these models need to be validated with experimental flux measurements to accurately predict intracellular metabolic fluxes [11]. While extracellular fluxes can be measured by estimating changes in external metabolite concentrations, intracellular flux measurements are difficult because ${ }^{13} \mathrm{C}$ NMR labeling is usually required [12]. We developed a genome-scale metabolic model (iMM518) for M. maripaludis S2 [13], but the model had not been fully validated due to inadequate quantitative data on uptake and production rates.

In this study, we performed batch culture experiments and quantified three key extracellular fluxes $\left(\mathrm{CO}_{2}, \mathrm{H}_{2}\right.$, and $\mathrm{CH}_{4}$ ) and specific growth rates of $M$. maripaludis. To the best of our knowledge, this is the first experimental study to report $\mathrm{CO}_{2}, \mathrm{H}_{2}$ consumption and $\mathrm{CH}_{4}$ production rates with $\mathrm{CO}_{2}$ as the sole carbon source. In addition, this study presents novel approaches to quantify extracellular fluxes and determine maintenance energy parameters using experimentally measured extracellular fluxes along with a genome-scale model. Using the model, we analyzed the effects of amino acids on growth rates, $\mathrm{CO}_{2}$ utilization rates, and $\mathrm{CH}_{4}$ production rates, and studied the distribution of carbon flux between biomass synthesis and methanogenesis.

\section{Results and discussion Cell growth}

Methanococcus maripaludis grew extremely well on $\mathrm{CO}_{2}$ without any complex substrates, such as acetate and yeast extract. The measured cell growth profile for M. maripaludis is shown in Fig. 1. The dry cell biomass increased by $15.49 \mathrm{mg}$ in $7 \mathrm{~h}$. The doubling time was about $2 \mathrm{~h}$, which is consistent with the literature [4]. The lag phase

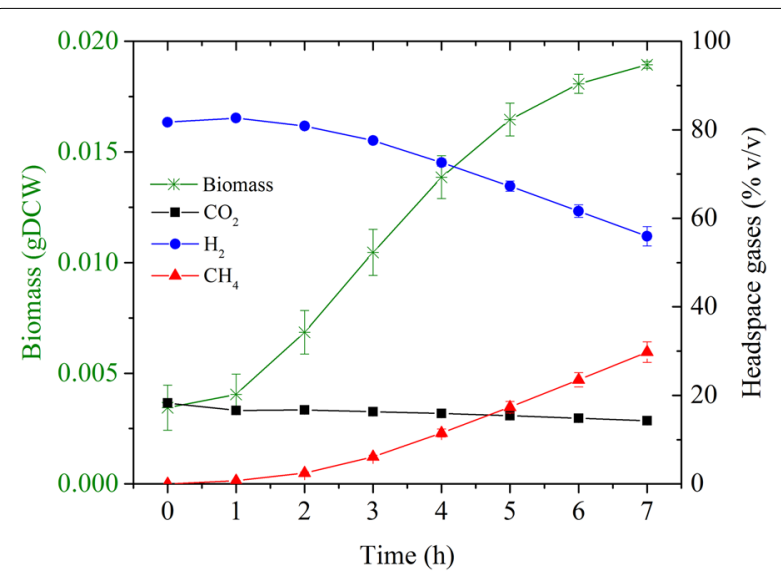

Fig. 1 Profiles of headspace gas compositions and biomass of $M$. maripaludis $\mathrm{S} 2$ in batch cultures under minimal media conditions using $\mathrm{CO}_{2}$ as the sole carbon substrate. $g D C W$ gram dry cell weight

duration varied with the state of inoculum, and found to be the shortest for an inoculum from the late exponential phase (data not shown). Figure 1 also shows the concentration profiles (\% v/v) of $\mathrm{CO}_{2}, \mathrm{H}_{2}$, and $\mathrm{CH}_{4}$ in the headspace of the reactor over a period of about $7 \mathrm{~h}$. The headspace pressure dropped from 250 to $100 \mathrm{kPa}$. The headspace contained $80 / 20 \mathrm{v} / \mathrm{v} \mathrm{H}_{2} / \mathrm{CO}_{2}$ at time zero. The metabolic/biocatalytic action of $M$. maripaludis increased methane concentration in the headspace to approximately $30 \% \mathrm{v} / \mathrm{v}$ at the end of $7 \mathrm{~h}$.

As the headspace pressure decreased with time, both growth rates and extracellular fluxes decreased (Fig. 2). The maximum growth rate was estimated to be $0.50 \pm 0.05 / \mathrm{h}$ for a $\mathrm{CO}_{2}$ uptake of $132.13 \pm 15.13 \mathrm{mmol} /$ $\mathrm{gDCW} / \mathrm{h}, \mathrm{H}_{2}$ uptake of $423.06 \pm 44.94 \mathrm{mmol} / \mathrm{gDCW} / \mathrm{h}$, and $\mathrm{CH}_{4}$ production of $105.61 \pm 17.75 \mathrm{mmol} / \mathrm{gDCW} / \mathrm{h}$. Kral et al. [14] reported a $\mathrm{H}_{2}$ uptake of $28.8 \mathrm{mmol} /$

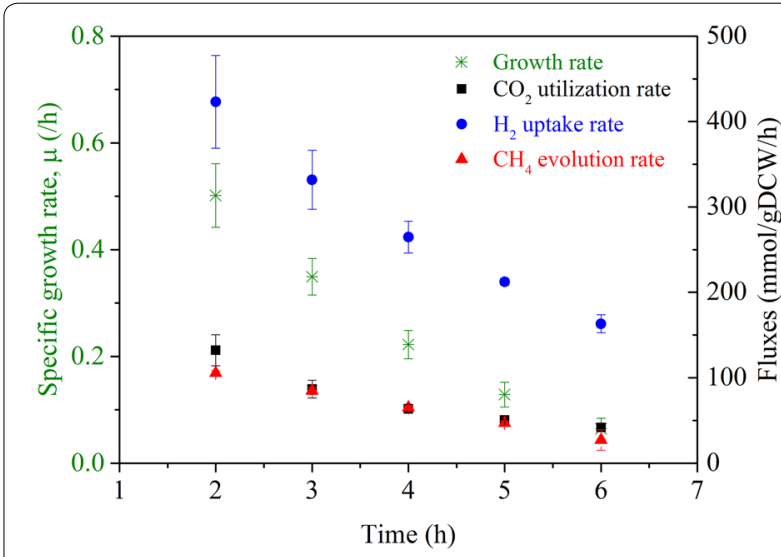

Fig. 2 The time profiles of specific growth rates and corresponding extracellular fluxes $\left(\mathrm{CO}_{2}, \mathrm{H}_{2}\right.$, and $\left.\mathrm{CH}_{4}\right)$ 
$\mathrm{gDCW} / \mathrm{h}$ in inorganic media. However, they did not state the growth phase for this rate. Our observed $\mathrm{H}_{2}$ uptake was $423.06 \pm 44.94 \mathrm{mmol} / \mathrm{gDCW} / \mathrm{h}$ in the early exponential phase, and $107.5 \pm 44.94 \mathrm{mmol} / \mathrm{gDCW} / \mathrm{h}$ at the end of $7 \mathrm{~h}$, suggesting that the rate reported by Kral et al. [14] might be measured for a late exponential phase. Lupa et al. [6] reported methane evolution rates (MERs) ranging from 9.40 to $27.55 \mathrm{mmol} / \mathrm{gDCW} / \mathrm{h}$ for cell growth rates of $0.04-0.13 / \mathrm{h}$, which is close to our MER of $27.19 \pm 17.75 \mathrm{mmol} / \mathrm{gDCW} / \mathrm{h}$ for a growth rate of $0.064 \pm 0.049 / \mathrm{h}$ in the late exponential phase. Apart from these two studies, no other data have been reported in the literature for the uptake and production rates of M. maripaludis. Thus, our study is the first to give a full range of comprehensive growth and flux data for $M$. maripaludis. In fact, we could not find similar data for any other methanogen except for one study [15] on M. barkeri, which reported a maximum $\mathrm{H}_{2}$ uptake rate of $41 \mathrm{mmol} / \mathrm{gDCW} / \mathrm{h}$ with a corresponding $\mathrm{CO}_{2}$ uptake rate of $11.61 \mathrm{mmol} / \mathrm{gDCW} / \mathrm{h}$ and $\mathrm{CH}_{4}$ production rate of $8.82 \mathrm{mmol} / \mathrm{gDCW} / \mathrm{h}$. Our observed fluxes are one order of magnitude higher than those reported for M. barkeri, which could be attributed to the doubling time of $M$. maripaludis $(\sim 2 \mathrm{~h})$ being much shorter than that of $M$. barkeri $(\sim 30 \mathrm{~h})$.

From the plot of dry cell weight $(\mathrm{g})$ versus methane produced over time, we obtained a growth yield of $3.549 \pm 0.149 \mathrm{gDCW} / \mathrm{molCH}_{4}$ for $M$. maripaludis during the exponential phase. Table 1 shows a comparison of growth yield and specific growth rate for different methanogens. The yield of $M$. maripaludis matches well with the yield reported for other hydrogenotrophic methanogens growing on $\mathrm{H}_{2} / \mathrm{CO}_{2}$ in batch cultures [16, 17]. Although a much higher yield on $\mathrm{H}_{2} / \mathrm{CO}_{2}(8.7 \pm 0.8$ $\mathrm{gDCW} / \mathrm{mol} \mathrm{CH}_{4}$ ) was reported in $M$. barkeri [18], the specific growth rate of $M$. maripaludis observed in this study $(0.346 / \mathrm{h})$ was 5.97 -fold higher than that in $M$. barkeri $(0.058 / \mathrm{h})$ [18]. A high specific growth rate suggests that $M$. maripaludis can grow rapidly and have good potentials for industrial and environmental applications.

\section{Extracellular fluxes}

Using the data from Fig. 2, the extracellular fluxes $\left(\mathrm{CO}_{2}, \mathrm{H}_{2}\right.$, and $\left.\mathrm{CH}_{4}\right)$ are correlated linearly with specific growth rates in Fig. 3. Using these linear correlations, we obtained the following relations among the extracellular fluxes:

$$
\begin{aligned}
& v_{\mathrm{H}_{2}} / \nu_{\mathrm{CO}_{2}}=2.858+64.759 / \nu_{\mathrm{CO}_{2}} \\
& v_{\mathrm{CH}_{4}} / \nu_{\mathrm{CO}_{2}}=0.854+1.855 / \nu_{\mathrm{CO}_{2}}
\end{aligned}
$$

Equation 2 suggests that the fraction of $\mathrm{CO}_{2}$ conversion to $\mathrm{CH}_{4}$ decreases with increase in $\mathrm{CO}_{2}$ uptake rate (or equivalently cell growth). This is consistent with the fact that cell growth competes with methanogenesis for carbon utilization [13]. When cell growth is low, most of the carbon is diverted to produce energy for maintenance via methanogenesis, resulting in a higher $\mathrm{CH}_{4}$ yield, and vice versa. Our observed conversion fraction for maximum growth rate is 0.868 , which is higher than 0.810 reported for $M$. barkeri in a chemostat culture grown on $\mathrm{H}_{2} / \mathrm{CO}_{2}$ [19].

Gas-to-liquid mass transfer of $\mathrm{O}_{2}, \mathrm{CO}_{2}, \mathrm{H}_{2}, \mathrm{~N}_{2}$ etc. plays an important role in the cultivation of microbes [20]. Various factors such as gas-liquid interfacial area, mixing, temperature, and pressure affect this mass transfer. Thus, we expected higher uptake rates of $\mathrm{CO}_{2}$ and $\mathrm{H}_{2}$ in M. maripaludis with enhanced mass transfer. To confirm this, we tested the effect of mixing and gas-liquid interfacial area on the growth and metabolism of $M$. maripaludis $S 2$ at $37^{\circ} \mathrm{C}$. Increasing the gas-liquid interfacial area by positioning the bottle reactor from vertical to horizontal roughly doubled MER, while shaking the reactor increased it multiple folds (data not shown).

\section{GAM, NGAM, and ATP gain}

Microorganisms carry out catabolic oxidation-reduction reactions to obtain energy for growth and cell maintenance. These energy usages are captured in a genomescale model in the form of two parameters, growth associated maintenance (GAM mmolATP/gDCW) and

Table 1 Quantitative comparison of growth yields and specific growth rates for some methanogens

\begin{tabular}{lllll}
\hline Organism & Substrate & Yield, $\mathbf{Y}_{\mathbf{C H} \mathbf{4}}$ (gDCW/molCH & Specific growth rate, $\boldsymbol{\mu}(\mathbf{h})$ & References \\
\hline M. thermoautotrophicum & $\mathrm{H}_{2}, \mathrm{CO}_{2}$ & $1.6-3$ & 0.690 & {$[16]$} \\
M. bryantii & $\mathrm{H}_{2}, \mathrm{CO}_{2}$, organic supplements & 2.4 & 0.031 & {$[32]$} \\
M. str $\mathrm{AZ}$ & $\mathrm{H}_{2}, \mathrm{CO}_{2}$ & 2.32 & 0.110 & {$[33]$} \\
M. barkeri & $\mathrm{H}_{2}, \mathrm{CO}_{2}$ & 8.7 & 0.058 & {$[18]$} \\
M. formicicum & $\mathrm{H}_{2}, \mathrm{CO}_{2}$, organic supplements & 3.5 & 0.060 & {$[34]$} \\
M. maripaludis & $\mathrm{H}_{2}, \mathrm{CO}_{2}$ & 3.54 & 0.346 & This study \\
\hline
\end{tabular}

gDCW gram dry cell weight 


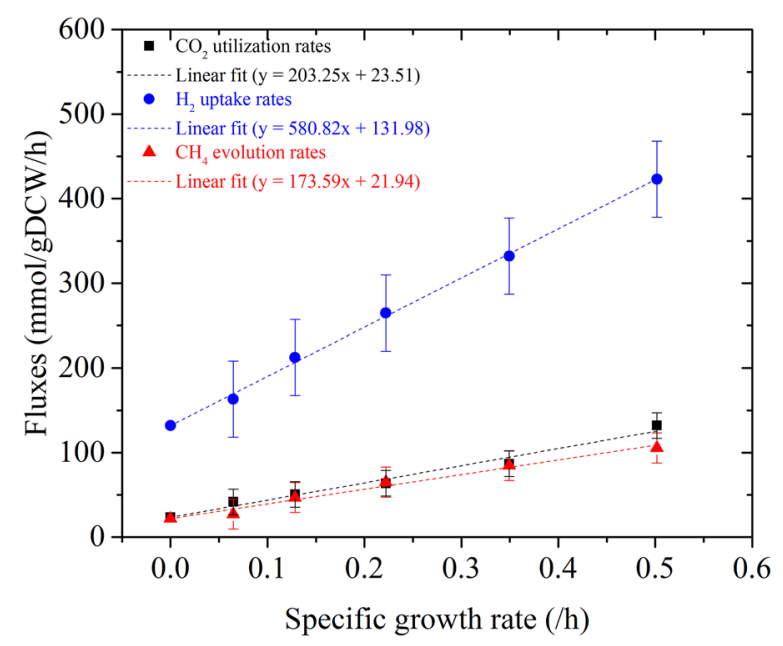

Fig. 3 Linear correlations between extracellular fluxes and specific growth rates

non-growth associated maintenance (NGAM mmolATP/ $\mathrm{gDCW} / \mathrm{h})$. GAM represents the energy required for the polymerization of macromolecules, such as DNA, RNA, proteins, and glycogen, during growth. It appears as the stoichiometric coefficient of ATP in the reaction representing biomass formation (cell growth) in iMM518. In contrast, NGAM represents the energy (mmolATP/ $\mathrm{gDCW} / \mathrm{h}$ ) required for cell repair, motility, maintenance of ion gradients etc., which the cell uses in addition to GAM [21, 22].

While it is possible to theoretically estimate GAM, it is not possible to estimate NGAM. Using a literature procedure [23], we estimated GAM as $30.0 \mathrm{mmolATP} / \mathrm{gDCW}$ for $M$. maripaludis. Although literature did not report any values for GAM and NGAM for $M$. maripaludis, we were able to estimate them using $i$ MM518 and with our comprehensive experimental data in this study. Our earlier validation of $i$ MM518 was based on limited biomass growth data and phenotypic observations on gene knock-outs due to the unavailability of experimentally measured fluxes [13]. In this study, we are presenting a novel procedure to estimate GAM and NGAM precisely for $M$. maripaludis, and validating our model predictions for extracellular fluxes.

Our experiments indicated that cell growth rate was zero at a $\mathrm{CO}_{2}$ uptake of $23.51 \mathrm{mmol} / \mathrm{gDCW} / \mathrm{h}$, and the non-growth maintenance energy that gave zero growth prediction from $i$ MM518 was $7.836 \mathrm{mmolATP} / \mathrm{gDCW} / \mathrm{h}$. Thus, NGAM was calculated as 7.836 mmolATP/ $\mathrm{gDCW} / \mathrm{h}$. NGAM was then fixed in the model and the total Sum of Squares of Errors (TSSE) was calculated for a range of GAM values. Figure 4 shows how TSSE varied with GAM. TSSE was minimum at GAM $=27.14$

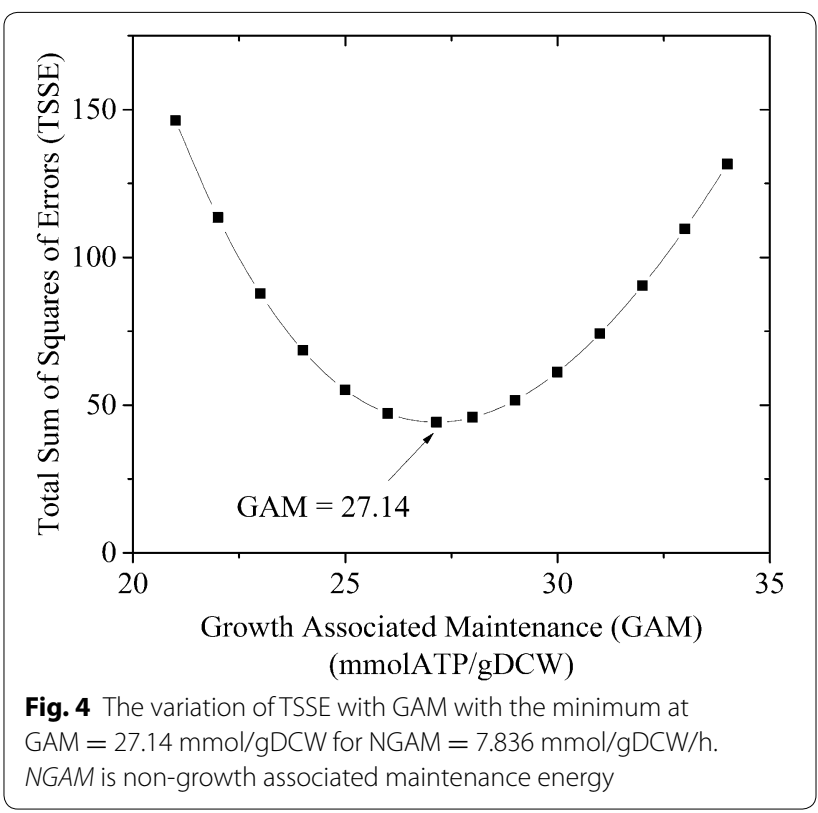

mmolATP/gDCW, which is the best estimate of GAM from our experiments. The deviations in $\mathrm{H}_{2}$ uptake predictions contributed the most $(67.4 \%)$ to the minimum TSSE $=0.044$, followed by those in $\mathrm{CH}_{4}$ evolution rates $(31.7 \%)$. The prediction of biomass growth from the model matched very well with the experimental values. Model predictions of growth rates showed less than $1 \%$ $(0.76 \%)$ deviations from measured values. Our estimated GAM of 27.14 mmolATP/gDCW/h agrees very well with the theoretical estimate of $30.0 \mathrm{mmolATP} / \mathrm{gDCW} / \mathrm{h}$ ) [13] for M. maripaludis. Table 2 lists GAM and NGAM reported for selected microorganisms in the literature.

A common method for estimating GAM and NGAM is to measure substrate uptake fluxes (mmol substrate/ $\mathrm{gDCW} / \mathrm{h}$ ) at different growth rates and use an estimated ATP gain (mol ATP/mol substrate). However, the difficulty with this approach is that precise values for ATP gains are unavailable for most microbes including $M$. maripaludis, as it is difficult to assess the amount of ATP generation per mole of substrate or product. In contrast, our approach combines experimentally measured values along with a genome-scale model to estimate NGAM and GAM without requiring an ATP gain. In fact, we estimated ATP gains from our NGAM as $0.33 \mathrm{~mol} \mathrm{ATP/}$ $\mathrm{mol} \mathrm{CO}, 0.35 \mathrm{~mol} \mathrm{ATP} / \mathrm{mol} \mathrm{CH}_{4}$, and $0.238 \mathrm{~mol} \mathrm{ATP} /$ mol $\mathrm{H}_{2}$. While the ATP gains from $\mathrm{CO}_{2}$ and $\mathrm{CH}_{4}$ are similar, the ATP gain from $\mathrm{H}_{2}$ is much lower. This could be due to the deviations observed in our flux predictions for $\mathrm{H}_{2}$ in TSSE. The value of $0.35 \mathrm{molATP} / \mathrm{molCH}_{4}$ is in the acceptable range of $0.3-0.7 \mathrm{~mol} \mathrm{ATP} / \mathrm{molCH}_{4}$ reported for microbes with autotrophic growth on $\mathrm{H}_{2} / \mathrm{CO}_{2}$ [24]. Kaster et al. [25] suggested an ATP gain of less than 1 mol 
Table 2 Comparison of our estimated GAM and NGAM for M. maripaludis with those reported for other model organisms

\begin{tabular}{lllll}
\hline Organism & Substrate & GAM (mmol/gDCW) & NGAM (mmol/gDCW/h) & References \\
\hline Escherichia coli & Glucose & 59.81 & 8.39 & {$[35]$} \\
Lactococcus lactis & Different sugar substrates e.g. mannose, & 18.15 & 1 & {$[36]$} \\
Methanosarcina barkeri & $\quad$ Malactose, sucrose, lactose, etc. & & & \\
Methanosarcina acetivorans & CO or methanol & 70 & 1.75 & {$[15]$} \\
Methanococcus maripaludis & $\mathrm{H}_{2} / \mathrm{CO}_{2}$ & 65 & 2.5 & {$[37]$} \\
\hline
\end{tabular}

GAM growth associated maintenance energy, NGAM non-growth associated maintenance energy

$\mathrm{ATP} / \mathrm{mol} \mathrm{CH}_{4}$ for methanogens without cytochromes (e.g. M. maripaludis) and more than $1 \mathrm{~mol} \mathrm{ATP} / \mathrm{mol} \mathrm{CH}_{4}$ for methanogens with cytochromes (e.g. M. barkeri). Thus, our estimate of $0.35 \mathrm{~mol} \mathrm{ATP} / \mathrm{mol} \mathrm{CH}_{4}$ is in agreement with the literature.

With $\mathrm{GAM}=27.14 \mathrm{mmol} / \mathrm{gDCW}$ and $\mathrm{NGAM}=$ $7.836 \mathrm{mmol} / \mathrm{gDCW} / \mathrm{h}$ in $i \mathrm{MM} 518$, we fixed $\mathrm{CO}_{2}$ uptake rate at various values and predicted cell growth, MER, and $\mathrm{H}_{2}$ uptake rate for the maximum biomass growth. Figure 5 compares experimental results with our model predictions. As we can see, our model predictions and experimental results match very well.

\section{Intracellular fluxes}

Genetic and/or environmental perturbations can change extracellular or intracellular fluxes in an organism. If a genome-scale model can be used to simulate these perturbations, then it can help us study phenotypes under various culture conditions, improve microbial strains in bioprocesses, analyze multispecies relationships, etc. Therefore, we further applied iMM518 to study the impacts of various experimentally studied or hypothetical

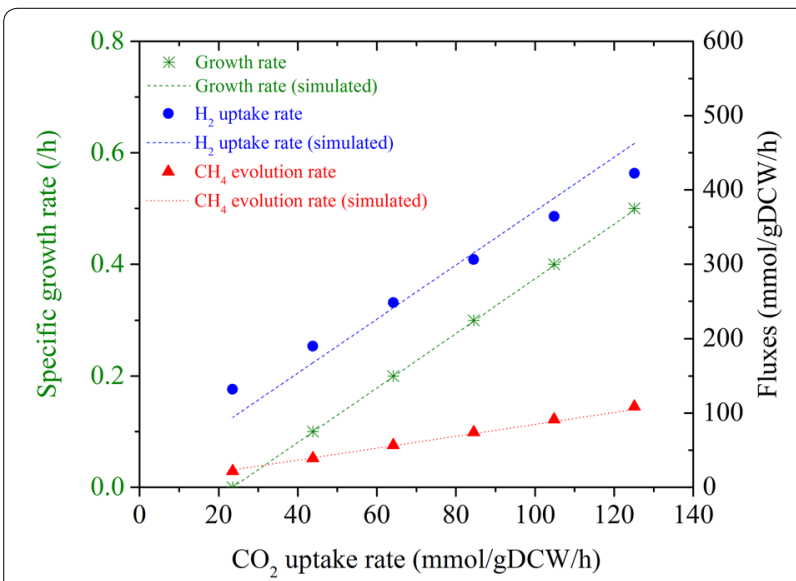

Fig. 5 Comparison of model predicted growth rates, $\mathrm{H}_{2}$ uptake rates, and $\mathrm{CH}_{4}$ evolution rates with experimentally measured values for fixed $\mathrm{CO}_{2}$ uptake rates scenarios on the distribution of intracellular fluxes in $M$. maripaludis S2.

\section{Effects of amino acids and vitamins from iMM518}

The amino acids are known to stimulate the growth of autotrophic methanococci $[26,27]$, but the precise mechanisms behind these stimulations and the effects of amino acids on methanogenesis are unknown. To study these, we first modeled a culture with all amino acids. We fixed $\mathrm{CO}_{2}$ uptake at $60 \mathrm{mmol} / \mathrm{gDCW} / \mathrm{h}$ in $i \mathrm{MM} 518$, and allowed unlimited uptakes for all amino acids. As compared to the scenario with no amino acids in the culture, the cell growth increased by $44.4 \%$, and MER increased by $11.2 \%$. The former is consistent with previous experimental observations at least qualitatively [26, 27], while the latter has not been measured in the literature. M. maripaludis prefers alanine overwhelmingly over all other amino acids, as the uptake distribution was alanine $34.6 \mathrm{~mol} \%$, aspartate $14.4 \mathrm{~mol} \%$, serine $13.7 \mathrm{~mol} \%$, leucine $5.8 \mathrm{~mol} \%$, valine $4.6 \mathrm{~mol} \%$, and the rest $<5.0 \mathrm{~mol} \%$. M. maripaludis avoids the uptake of glycine, tyrosine, glutamate and glutamine.

In order to study the effects of amino acids individually, we performed 20 culture simulations with single amino acid each in $i$ MM518. Interestingly, the uptakes and effects were quite different from what we observed with all amino acids in one culture simulation (Fig. 6). This could be primarily because the microbe prefers some amino acids over others for energetic reasons. Table 3 lists the changes in cell growth and MER due to each amino acid. Alanine proved the most effective for growth and MER, as it increased growth by $11.4 \%$ and MER by $10.3 \%$. In contrast to the earlier scenario with all amino acids, the microbe consumed aspartate, and growth increased by $11.5 \%$ and MER by $3.0 \%$. All other amino acids individually increased growth rate by less than $7 \%$. To evaluate the differences in the increments of growth and MER between alanine and aspartate, we examined the distribution of intracellular fluxes in both cases. Alanine served as the sole nitrogen source which has been confirmed by previous experiments [26]. On the other hand, aspartate could not supply the entire 


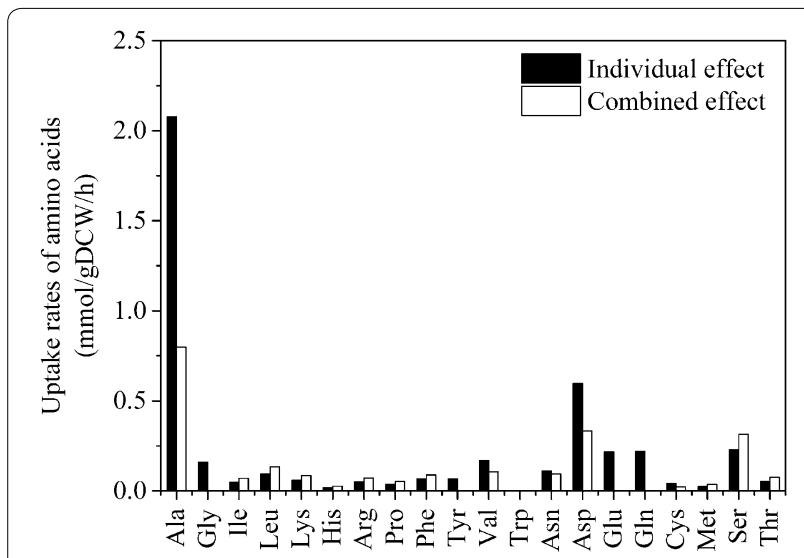

Fig. 6 In silico uptake rates of amino acids when supplied individually versus all-together in the culture medium

Table 3 Individual and combined effects of amino acids on growth rates, $\mathrm{H}_{2}$ uptake rates, and $\mathrm{CH}_{4}$ evolution rates as predicted by $\mathrm{iMM} 518$

\begin{tabular}{lccc}
\hline Amino acids & $\begin{array}{l}\text { \% increment } \\
\text { in specific } \\
\text { growth rates }\end{array}$ & $\begin{array}{l}\text { \% increment } \\
\text { in } \mathbf{H}_{\mathbf{2}} \text { uptake } \\
\text { rates }\end{array}$ & $\begin{array}{l}\text { \% increment } \\
\text { in } \mathrm{CH}_{\mathbf{4}} \text { evolution } \\
\text { rates }\end{array}$ \\
\hline Alanine & 11.38 & 4.82 & 10.25 \\
Glycine & 2.19 & 0.22 & 0.31 \\
Isoleucine & 0.79 & 0.14 & 0.44 \\
Leucine & 1.54 & 0.28 & 0.86 \\
Lysine & 1.97 & 0.15 & 0.41 \\
Histidine & 1.50 & 0.02 & -0.01 \\
Arginine & 2.25 & -0.09 & -0.21 \\
Proline & 0.30 & -0.05 & -0.04 \\
Phenylalanine & 6.52 & 0.28 & 0.61 \\
Tyrosine & 6.52 & 0.31 & 0.61 \\
Valine & 2.32 & 0.46 & 1.29 \\
Tryptophan & 0.14 & 0.00 & 0.01 \\
Asparagine & 3.06 & 0.31 & 0.43 \\
Aspartate & 11.46 & 1.95 & 2.95 \\
Glutamate & 0.00 & 0.00 & 0.00 \\
Glutamine & 1.82 & -0.11 & -0.25 \\
Cysteine & 0.55 & 0.09 & 0.15 \\
Methionine & 0.46 & 0.06 & 0.12 \\
Serine & 3.74 & 0.48 & 0.78 \\
Threonine & 1.89 & 0.07 & 0.14 \\
Combined & 44.39 & 11.17 & 5.4 \\
\hline
\end{tabular}

nitrogen demands of the cell, but acted as a supplement to reduce ammonium uptake by $25.9 \%$. Alanine increased growth primarily by supplying additional pyruvate via the reaction alanine $+\mathrm{NAD}+\mathrm{H}_{2} \mathrm{O} \leftrightarrow$ pyruvate $+\mathrm{NH}_{3}+\mathrm{NADH}+\mathrm{H}$, which in turn increased the biosynthesis of cell growth precursors such as amino acids. Most of the $\mathrm{CO}_{2}$ was diverted to methane production to provide the energy for the additional growth, and hence MER also increased. The model also predicted that the autotrophic formation of acetyl-CoA drastically reduced (approx. 65.4\%) with alanine in medium. This is consistent with previous experimental results that alanine is an efficient means of labeling pyruvate, as only $3-5 \%$ of the carbon in acetyl-CoA was from $\mathrm{CO}_{2}$ [28]. On the other hand, aspartate did not contribute significantly towards the formation of pyruvate and only $10 \%$ drop in the flux was observed for the formation of acetyl$\mathrm{CoA}$ from $\mathrm{CO}_{2}$.

Interestingly, several amino acids such as arginine, histidine, proline and glutamine showed marginally reduced $(<0.1 \%)$ MERs. This is because the cell saved the energy for making these amino acids. Methanogenesis, being the only energy producing pathway in M. maripaludis, reduced MER accordingly. Our in silico study showed that none of the vitamins including water-soluble riboflavin, biotin, and vitamin B12 affected growth at all. This is again validated by a previous experimental study [26], and needs no repeat experimental validation.

\section{Conclusions}

Our experimental measurements of extracellular fluxes were in excellent agreement with in silico predictions of $i \mathrm{MM} 518$ at GAM $=27.14 \mathrm{mmol} / \mathrm{gDCW}$ and $\mathrm{NGAM}=7.836 \mathrm{mmol} / \mathrm{gDCW} / \mathrm{h}$, thus allowed us to elucidate the physiological and metabolic states of the cells during batch culture. With $M$. maripaludis, an instantaneous conversion of 85-95\% from $\mathrm{CO}_{2}$ to $\mathrm{CH}_{4}$ was observed at $37{ }^{\circ} \mathrm{C}$, while the conversion on a metal catalyst did not go beyond $70 \%$ even at $800{ }^{\circ} \mathrm{C}$ [1]. Understanding biofuel production from methanogens will help scientists develop a bioreactor employing immobilized enzymes instead of a whole cell bioreactor. It is also possible to perform methanogenesis from $\mathrm{CO}_{2}$ at a very fast rate and avoid wasteful microbial biomass without the need for biofuel extraction.

Biochemical conversion of $\mathrm{CO}_{2}$ to biofuels using such strategies provides a promising route for more efficient renewable energy production. It should be noted that the cellular objective could be different depending on environmental or physiological conditions, with considerable implication on the final cellular phenotype [29]. For example, maximizing the growth rate during stationary phase may not be cellular objective. In that case it is important to identify the most plausible cellular objectives, such as minimization of ATP production, maximization of metabolite production, and minimization of nutrient uptake, and the predictive power a genomicscale model can be greatly improved. 


\section{Methods}

\section{Chemicals and gases}

All chemicals used in this study were American Chemical Society (ACS) analytical reagents purchased from SigmaAldrich. Pure gases $\left(\mathrm{N}_{2}\right.$, Ar) and $80 / 20 \mathrm{v} / \mathrm{v} \mathrm{H}_{2} / \mathrm{CO}_{2}$ mixture were purchased from AIR Liquide, Singapore.

\section{Strain and medium}

Methanococcus maripaludis S2 (DSM 14266) was purchased from DSMZ-German Collection of Microorganisms and Cell Cultures. Methanococcus culture medium 141 was used to cultivate the culture at $37{ }^{\circ} \mathrm{C}$ with a headspace pressure of $200 \mathrm{kPa}$ under $80 / 20 \mathrm{H}_{2} /$ $\mathrm{CO}_{2}$ and constantly stirred at $180 \mathrm{rpm}$ [30]. The minimal medium for the growth experiments comprised $0.34 \mathrm{~g}$ of $\mathrm{KCl}, 4 \mathrm{~g}$ of $\mathrm{MgCl}_{2} \cdot 6 \mathrm{H}_{2} \mathrm{O}, 3.45 \mathrm{~g}$ of $\mathrm{MgSO}_{4} \cdot 7 \mathrm{H}_{2} \mathrm{O}, 0.25 \mathrm{~g}$ of $\mathrm{NH}_{4} \mathrm{Cl}, 0.14 \mathrm{~g}$ of $\mathrm{CaCl}_{2} \cdot 2 \mathrm{H}_{2} \mathrm{O}, 0.14 \mathrm{~g}$ of $\mathrm{K}_{2} \mathrm{HPO}_{4}$, $18 \mathrm{~g}$ of $\mathrm{NaCl}, 10 \mathrm{~mL}$ of trace elements, and $2 \mathrm{mg}$ of $\mathrm{Fe}\left(\mathrm{NH}_{4}\right)_{2}\left(\mathrm{SO}_{4}\right)_{2} \cdot 7 \mathrm{H}_{2} \mathrm{O}$ per liter. The trace element solution comprised $3 \mathrm{~g} \mathrm{MgSO}_{4} \cdot 7 \mathrm{H}_{2} \mathrm{O}, 0.5 \mathrm{~g} \mathrm{MnSO}_{4} \cdot \mathrm{H}_{2} \mathrm{O}$, $1 \mathrm{~g} \mathrm{NaCl}, 0.10 \mathrm{~g} \mathrm{FeSO} \cdot 7 \mathrm{H}_{2} \mathrm{O}, 0.18 \mathrm{~g} \mathrm{CoSO} \cdot 7 \mathrm{H}_{2} \mathrm{O}$, $0.10 \mathrm{~g} \quad \mathrm{CaCl}_{2} \cdot 2 \mathrm{H}_{2} \mathrm{O}$., $0.18 \mathrm{~g} \quad \mathrm{ZnSO}_{4} \cdot 7 \mathrm{H}_{2} \mathrm{O}, \quad 0.01 \mathrm{~g}$ $\mathrm{CuSO}_{4} \cdot 5 \mathrm{H}_{2} \mathrm{O}, 0.02 \mathrm{~g} \mathrm{KAl}\left(\mathrm{SO}_{4}\right)_{2} \cdot 12 \mathrm{H}_{2} \mathrm{O}, 0.01 \mathrm{~g} \mathrm{H}_{3} \mathrm{BO}_{3}$, $0.01 \mathrm{~g} \mathrm{Na} \mathrm{MoO}_{4} \cdot 2 \mathrm{H}_{2} \mathrm{O}, 0.03 \mathrm{~g} \mathrm{NiCl} \cdot 6 \mathrm{H}_{2} \mathrm{O}, 0.30 \mathrm{mg}$ $\mathrm{Na}_{2} \mathrm{SeO}_{3} \cdot 5 \mathrm{H}_{2} \mathrm{O}$, and $990 \mathrm{~mL}$ DI $\mathrm{H}_{2} \mathrm{O}$. Soluble carbon source and cysteine were removed and $\mathrm{CO}_{2}$ was the only carbon source. Vitamins were also omitted [26].

\section{Batch cultivation}

$230 \mathrm{~mL}$ of medium was dispensed into $600 \mathrm{~mL}$ serum bottles, and sparged with $80 / 20 \mathrm{v} / \mathrm{v} \mathrm{H}_{2} / \mathrm{CO}_{2}$ to remove dissolved oxygen and create an anaerobic atmosphere. After autoclaving at $121{ }^{\circ} \mathrm{C}$ for $20 \mathrm{~min}$, the bottles were cooled to room temperature and $0.5 \mathrm{mg} / \mathrm{mL}$ of $\mathrm{Na}_{2} \mathrm{~S} \cdot 7 \mathrm{H}_{2} \mathrm{O}$ was injected. To initiate the growth in minimal medium, $20 \mathrm{~mL}$ of inoculum (pre-cultured cells in late exponential phase) was injected into each bottle. The bottles were then pressurized with $250 \mathrm{kPa} 80 / 20 \mathrm{v} / \mathrm{v} \mathrm{H}_{2} /$ $\mathrm{CO}_{2}$ and incubated at $37{ }^{\circ} \mathrm{C}$ under constant stirring at $180 \mathrm{rpm}$. Cell density and concentrations of $\mathrm{CO}_{2}, \mathrm{H}_{2}$, and $\mathrm{CH}_{4}$ in the headspace were measured. The growth experiments were discontinued when the headspace pressure fell below $100 \mathrm{kPa}$ to avoid the inflow of air into the reactor. All growth experiments were performed in duplicates accompanied by a control experiment with no inoculum.

\section{Analytical procedures}

Cellular growth was monitored by measuring optical density (OD) of $1 \mathrm{~mL}$ culture samples during the experiments. OD was recorded at $600 \mathrm{~nm}$ using a double-beam UV/Vis Spectrophotometer (Hitachi Model U-2800, High Technologies America, Inc.). Our OD measurements had a standard deviation of $3.35 \times 10^{-3}$. Bottle pressure was measured using a M1 digital pressure gauge (Cole Parmer, USA) with sensitivity of $10^{-4}$ bar. Headspace gases were analyzed with an Agilent 7890A series SRI Instrument GC equipped with three columns (a Porapak Q 80/100 SS packed column of size $6 \mathrm{ft} \mathrm{L} \times 1 / 8^{\prime \prime}$ OD $\times 2 \mathrm{~mm}$ ID, a Molecular Sieve 5A 80/100 SS packed column of size $3 \mathrm{ft} \mathrm{L} \mathrm{1/8"} \mathrm{OD} 2 \mathrm{~mm}$ ID, and a Hayesep T 80/100 UM column of size $0.5 \mathrm{~m} \mathrm{~L} \mathrm{1/8"} \mathrm{OD} 2 \mathrm{~mm}$ ID) and a thermal conductivity detector with electronic pneumatic control (EPC). The carrier gas (Ar) was continuously supplied at 100 psig. $\mathrm{N}_{2}$ was supplied at 30 psig to act as the actuation gas to compensate for the pressure and volume differences between the injected sample and required standard. The GC oven was maintained at $60^{\circ} \mathrm{C}$ and front detector at $150{ }^{\circ} \mathrm{C}$. $1 \mathrm{~mL}$ of gas samples were drawn from the bottles using gas airtight microsyringes (Hamilton Samplelock syringe), and analyzed immediately in GC. The GC was calibrated for dry gas compositions $(\% \mathrm{v} / \mathrm{v})$ using the series of standards.

\section{Cell growth measurements}

To estimate specific growth rate $(\mu)$, OD was measured at various time points. Lupa et al. [6] have reported an experimentally measured value $\left(1 O D_{600 \mathrm{~nm}}=0.34 \mathrm{~g}\right.$ $\mathrm{DCW} / L$ ) for converting OD to dry cell biomass specifically for $M$. maripaludis $S 2$. Using this, the measured OD values were converted to biomass given by $\mathrm{X}$ $\mathrm{gDCW}=\mathrm{OD} \times 0.34 \mathrm{~g} / \mathrm{L} \times$ culture volume and specific growth rate $(\mathrm{dX} / \mathrm{dt}) / \mathrm{X}$ was computed by curve-fitting and differentiating the time profile.

\section{Calculation of extracellular fluxes}

Estimating extracellular fluxes from a cell culture study is not straightforward as gases are distributed into both aqueous media and headspace. The fraction of gases in the aqueous medium depends on bottle temperature, pressure, mixing speed, and the solubility and dissociation properties of the gases in water. In order to estimate fluxes precisely, we simulated the dynamics of a $600 \mathrm{~mL}$ reactor using Aspen HYSYS V8.2 [31] for the entire experiment. The block flow diagram for this simulation is shown in Fig. 7. This method can also be used for all hydrogenotrophic methanogens that can grow on $\mathrm{CO}_{2}$ as the sole carbon substrate.

We simulated this initial state of the bottle by mixing sufficient amounts of pure water (stream 2), 80/20 $\mathrm{H}_{2} /$ $\mathrm{CO}_{2}$ (stream 1), and pure $\mathrm{CO}_{2}$ (stream 3). The flows of streams 1 and 2 were adjusted to achieve $350 \mathrm{~mL}$ headspace and $250 \mathrm{~mL}$ liquid medium, while the flow of stream 3 was adjusted to make the amount of $\mathrm{CO}_{2}$ in the headspace exactly equal to that supplied in stream 1. We measured culture OD, bottle pressure, bottle temperature, and headspace gas compositions. At each 


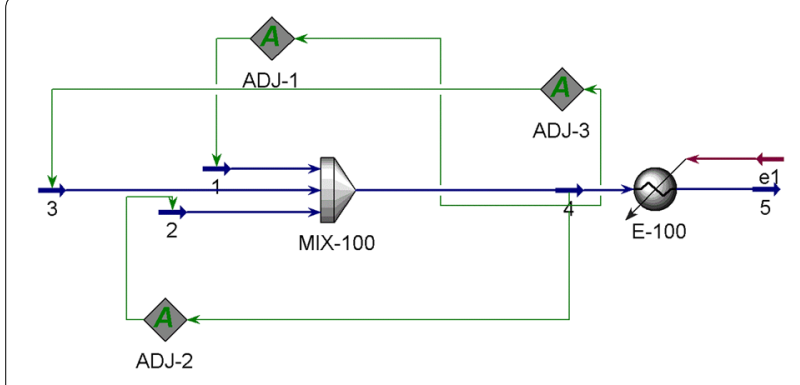

Fig. 7 Block flow diagram in Aspen Hysys for simulating the dynamics of a batch reactor

time point, we set stream 1 composition to be the same as the headspace composition (dry basis), the temperatures of streams 1,2 , and 3 as $37^{\circ} \mathrm{C}$, and the pressures of streams 1, 2, and 3 using the measured pressure. Then, we computed the total moles of $\mathrm{H}_{2}$ and $\mathrm{CH}_{4}$ in the botthe at each time point as the sum of moles of $\mathrm{H}_{2}\left(\mathrm{CH}_{4}\right)$ in the headspace from Hysys and moles of $\mathrm{H}_{2}\left(\mathrm{CH}_{4}\right)$ in the aqueous medium from Hysys. For computing the total moles of $\mathrm{CO}_{2}$ in the bottle, we also accounted for the high solubility $(1.05 \mathrm{~g} / \mathrm{L})$ and dissociation of $\mathrm{CO}_{2}$ into bicarbonates $\left(\mathrm{HCO}_{3}{ }^{-}\right)$and carbonates $\left(\mathrm{CO}_{3}{ }^{2-}\right)$. The initial $\mathrm{pH}$ of the growth culture was measured as 5.6, and it remained constant throughout the experiment (data not shown). Therefore, $\left[\mathrm{H}^{+}\right]$was fixed at $10^{-5.6}$ for the above calculations. Then, $\left[\mathrm{H}_{2} \mathrm{CO}_{3}\right]$ obtained from Aspen Hysys was used to compute other ionic concentrations. The total amount of $\mathrm{CO}_{2}$ at time $t$ was computed as the sum of $n\left(\mathrm{CO}_{2}\right)$ from Aspen Hysys, $\mathrm{HCO}_{3}{ }^{-}$, and $\mathrm{CO}_{3}{ }^{2-}$. The fluxes $v_{i}=1 / X(t) \cdot d n(i) / d t$ for $\mathrm{CO}_{2}$ and $\mathrm{H}_{2}$ consumption and $\mathrm{CH}_{4}$ production were computed by plotting the time profiles of total moles of $\mathrm{CO}_{2}, \mathrm{H}_{2}$, and $\mathrm{CH}_{4}$, where $n(i)$ is the moles of species $i\left(\mathrm{CO}_{2}, \mathrm{H}_{2}\right.$, or $\left.\mathrm{CH}_{4}\right)$ in the bottle and $X(t)$ is the dry cell mass (g DCW) at time $t$.

\section{Parameter estimation for iMM518}

$i$ MM518 is a genome-scale in silico metabolic model developed for M. maripaludis and is available in BioModel database as MODEL1304120000 [13]. It comprises 570 reactions and 556 distinct metabolites, and covers $518(\sim 30 \%)$ of the known 1722 open reading frames (ORFs). We implemented iMM518 in GAMS (build 38380/38394) and used CPLEX and BARON, respectively as the solvers for various linear and nonlinear optimization problems. $i$ MM518 uses two energy parameters: GAM and NGAM. We showed how the experimental data on fluxes and growth can be integrated with an in silico model (iMM518 in this case) to estimate GAM and NGAM. First, we used the time profiles of extracellular fluxes and specific growth rates to obtain a regression for each flux with growth rate, and estimated experimental growth rates for various $\mathrm{CO}_{2}$ uptake rates.

For flux balance analysis, we assumed the cellular objective to be maximum biomass. Then, to predict cell growth rate for a given $\mathrm{CO}_{2}$ uptake rate, we solved the following linear programming (LP) using iMM518.

$$
\text { Maximize } Z=\sum_{j=1}^{J} c_{j} v_{j} \text { subject to } S \cdot v=b
$$

where, $\mathrm{Z}$ is the cellular objective that is represented as a weighted sum of metabolite fluxes $v_{j}(j=1,2, \ldots, J)$ with weights $c_{j}, S$ is an $I \times J$ matrix of stoichiometric coefficients of the metabolic reactions, $I$ is the number of metabolites, $J$ is the number of metabolic reactions, $v$ is a $J \times 1$ vector of reaction fluxes, and $b$ is a $I \times 1$ vector of net metabolite fluxes.

The linear $\mathrm{CO}_{2}$ flux vs growth rate relationship reported above showed that cell growth was zero for a $\mathrm{CO}_{2}$ uptake rate below $23.51 \mathrm{mmol} / \mathrm{gDCW} / \mathrm{h}$, and we computed NGAM as the amount of energy spent for maintenance without growth. For estimating GAM, we selected twelve $\mathrm{CO}_{2}$ uptake rates $\left(v_{\mathrm{CO}_{2}}^{k}=b_{\mathrm{CO}_{2}}^{k}, \quad k=1,2, \ldots, 12\right)$. Using the $\mathrm{CO}_{2}$ flux vs growth rate expression, we computed respective experimental growth rates $\left(b_{G}^{k}, \quad k=1,2, \ldots, 12\right)$. We estimated the experimental fluxes $\left(b_{\mathrm{CH}_{4}}^{k}\right.$ and $\left.b_{\mathrm{H}_{2}}^{k}, \quad k=1,2, \ldots, 12\right)$ for $\mathrm{CH}_{4}$ and $\mathrm{H}_{2}$ at these $b_{G}^{k}$ using the linear expressions for $\mathrm{CH}_{4}$ and $\mathrm{H}_{2}$ fluxes vs growth rates. Further, we fixed the $\mathrm{CO}_{2}$ uptake rates inside $i$ MM518 to predict cell growth rates $\left(v_{G}^{k}, \quad k=1,2, \ldots, 12\right)$ and fluxes for $\mathrm{CH}_{4}\left(v_{\mathrm{CH}_{4}}^{k}\right)$ and $\mathrm{H}_{2}$ $\left(v_{\mathrm{H}_{2}}^{k}\right)$ for varying values of GAM. For each GAM value, we used these model predictions to compute a weighted sum of squares of errors (SSE) as follows:

$$
\begin{aligned}
\operatorname{SSE}(G A M)= & \sum_{k=1}^{12}\left[\gamma_{G}^{2}\left(v_{G}^{k}-b_{G}^{k}\right)^{2}\right. \\
& \left.+\gamma_{\mathrm{CH}_{4}}^{2}\left(v_{\mathrm{CH}_{4}}^{k}-b_{\mathrm{CH}_{4}}^{k}\right)^{2}+\gamma_{\mathrm{H}_{2}}^{2}\left(v_{\mathrm{H}_{2}}^{k}-b_{\mathrm{H}_{2}}^{k}\right)^{2}\right]
\end{aligned}
$$

where, $\gamma_{\mathrm{G}}=3 \mathrm{gDCW} / \mathrm{g}$ DCW, $\gamma_{\mathrm{CH} 4}=0.016 \mathrm{~g} / \mathrm{mmol}$, and $\gamma_{\mathrm{H} 2}=0.002 \mathrm{~g} / \mathrm{mmol}$. The GAM value with the minimum SSE was our best estimation for the growth energy required by $M$. maripaludis.

\section{Authors' contributions \\ NG performed experimental studies, collected and analyzed the data, imple- mented model, and wrote the manuscript. MP helped with experimental set-up and measurements. ZZ ensured the accuracy of experimental work, provided biological insights, and revised the manuscript. IAK contributed to the design of experiments, modeling and simulation, statistical analysis, and interpretation of data. IAK revised the manuscript and gave the final approval for submission. All authors read and approved the final manuscript.}

\section{Author details}

${ }^{1}$ Department of Chemical and Biomolecular Engineering, National University of Singapore, 4 Engineering Drive 4, Singapore 117585, Singapore. 
${ }^{2}$ Department of Civil and Environmental Engineering, National University of Singapore, 1 Engineering Drive 2, Singapore 117576, Singapore. ${ }^{3}$ Division of Environmental and Ecological Engineering and School of Civil Engineering, Purdue University, 550 Stadium Mall Drive, West Lafayette, IN 47907, USA.

\section{Acknowledgements}

The authors would like to acknowledge financial support for this work from the National University of Singapore through Graduate Research Scholarship to Miss Nishu Goyal and strategic funds under Grants R279-000-361-133/731 and R261-508-001-646/733. The authors thank Dr. Huang Kefeng for assistance during Hysys simulations. We also thank Professor Neal Chung at the National University of Singapore for providing us a series of gas standards for GC calibration.

\section{Compliance with ethical guidelines}

\section{Competing interests}

The authors declare that they have no competing interests.

Received: 2 July 2015 Accepted: 3 September 2015

Published online: 16 September 2015

\section{References}

1. Wei W, Jinlong G. Methanation of carbon dioxide: an overview. Front Chem Sci Eng. 2011;5:2-10.

2. Saini R, Kapoor R, Kumar R, Siddiqi TO, Kumar A. CO, utilizing microbes-a comprehensive review. Biotechnol Adv. 2011;29:949-60.

3. Jones W, Donnelly M, Wolfe R. Evidence of a common pathway of carbon dioxide reduction to methane in methanogens. J Bacteriol. 1985;163:126-31.

4. Jones WJ, Paynter MJB, Gupta R. Characterization of Methanococcus maripaludis sp. nov., a new methanogen isolated from salt marsh sediment. Arch Microbiol. 1983;135:91-7.

5. Kessler PS, Daniel C, Leigh JA. Ammonia switch-off of nitrogen fixation in the methanogenic archaeon Methanococcus maripaludis: mechanistic features and requirement for the novel GlnB homologues, Nif I (1) and Nifl(2). J Bacteriol. 2001;183:882-9.

6. Lupa B, Hendrickson EL, Leigh JA, Whitman WB. Formate-dependent $\mathrm{H}_{2}$ production by the mesophilic methanogen Methanococcus maripaludis. Appl Environ Microbiol. 2008;74:6584-90.

7. Kessler PS, Leigh JA. Genetics of nitrogen regulation in Methanococcus maripaludis. Genetics. 1999;152:1343-51.

8. Kessler PS, McLarnan J, Leigh JA. Nitrogenase phylogeny and the molybdenum dependence of nitrogen fixation in Methanococcus maripaludis. J Bacteriol. 1997;179:541-3.

9. Pires J, Alvim-Ferraz M, Martins F, Simões M. Carbon dioxide capture from flue gases using microalgae: engineering aspects and biorefinery concept. Renew Sustain Energy Rev. 2012;16:3043-53.

10. Price ND, Reed JL, Palsson BO. Genome-scale models of microbial cells: evaluating the consequences of constraints. Nat Rev Microbiol. 2004:2:886-97.

11. Zupke C, Stephanopoulos G. Intracellular flux analysis in hybridomas using mass balances and in vitro ${ }^{13} \mathrm{C}$ NMR. Biotechnol Bioeng. 1995:45:292-303.

12. Wiechert W. Metabolic flux determination by stationary ${ }^{13} \mathrm{C}$ tracer experiments: analysis of sensitivity, identifiability and redundancy. In: Doležal

J, Fidler J, editors. System modelling and optimization. USA: Springer; 1996. p. 128-35 (IFIP-The International Federation for Information Processing)

13. Goyal N, Widiastuti H, Karimi IA, Zhou Z. Genome-scale metabolic model of Methanococcus maripaludis $\mathrm{S} 2$ for $\mathrm{CO}_{2}$ capture and conversion to methane. Mol BioSyst. 2014;10:1043-54.

14. Kral TA, Brink KM, Miller SL, McKay CP. Hydrogen consumption by methanogens on the early earth. Orig Life Evol Biosph. 1998;28:311-9.

15. Feist AM, Scholten JCM, Palsson BØ, Brockman FJ, Ideker T. Modeling methanogenesis with a genome-scale metabolic reconstruction of Methanosarcina barkeri. Mol Syst Biol. 2006;2. doi:10.1038/msb4100046.
16. Taylor GT, Pirt SJ. Nutrition and factors limiting the growth of a methanogenic bacterium (Methanobacterium thermoautotrophicum). Arch Microbiol. 1977;113:17-22.

17. Woese CR, Magrum LJ, Fox GE. Archaebacteria. J Mol Evol. 1978;11:29-30.

18. Smith MR, Mah RA. Growth and methanogenesis by Methanosarcina strain 227 on acetate and methanol. Appl Environ Microbiol. 1978:36:870-9.

19. Weimer P, Zeikus J. One carbon metabolism in methanogenic bacteria. Arch Microbiol. 1978;119:49-57.

20. Pauss A, Andre G, Perrier M, Guiot SR. Liquid-to-gas mass transfer in anaerobic processes: inevitable transfer limitations of methane and hydrogen in the biomethanation process. Appl Environ Microbiol. 1990;56:1636-44.

21. Rozendal RA, Hamelers HV, Buisman CJ. Effects of membrane cation transport on $\mathrm{pH}$ and microbial fuel cell performance. Environ Sci Technol. 2006;40:5206-11.

22. Rozendal RA, Hamelers HV, Molenkamp RJ, Buisman CJ. Performance of single chamber biocatalyzed electrolysis with different types of ion exchange membranes. Water Res. 2007;41:1984-94.

23. Verduyn C, Stouthamer AH, Scheffers WA, Dijken JP. A theoretical evaluation of growth yields of yeasts. Antonie Van Leeuwenhoek. 1991:59:49-63.

24. Kates M, Kushner DJ, Matheson A. The biochemistry of archaea (archaebacteria). Amsterdam: Elsevier; 1993

25. Kaster A-K, Moll J, Parey K, Thauer RK. Coupling of ferredoxin and heterodisulfide reduction via electron bifurcation in hydrogenotrophic methanogenic archaea. Proc Natl Acad Sci. 2011;108:2981-6.

26. Whitman WB, Sohn S, Kuk S, Xing R. Role of amino acids and vitamins in nutrition of mesophilic Methanococcus spp. Appl Environ Microbiol. 1987;53:2373-8.

27. Wang $B, L i Y$, Wu N, Lan CQ. $C_{2}$ bio-mitigation using microalgae. App Microbiol Biotechnol. 2008;79:707-18.

28. Yang YL, Glushka JN, Whitman WB. Intracellular pyruvate flux in the methane-producing archaeon Methanococcus maripaludis. Arch Microbiol. 2002;178:493-8.

29. Leigh JA. Nitrogen fixation in methanogens: the archaeal perspective. Curr Issues Mol Biol. 2000;2:125-31.

30. Whitman WB, Shieh J, Sohn S, Caras DS, Premachandran U. Isolation and characterization of 22 mesophilic methanococci. Syst Appl Microbiol. 1986;7:235-40.

31. Burlington MA. HYSYS, ASPEN. A user guide manual. Aspen Technology. 2006.

32. Roberton A, Wolfe R. Adenosine triphosphate pools in Methanobacterium. J Bacteriol. 1970:102:43-51.

33. Zehnder AJB, Wuhrmann K. Physiology of a Methanobacterium strain Az. Arch Microbiol. 1977;111:199-205.

34. Schauer NL, Ferry JG. Metabolism of formate in Methanobacterium formicicum. J Bacteriol. 1980;142:800-7.

35. Feist AM, Henry CS, Reed JL, Krummenacker M, Joyce AR, Karp PD, Broadbelt $\sqcup$, Hatzimanikatis V, Palsson B $\emptyset$. A genome-scale metabolic reconstruction for Escherichia coli K-12 MG1655 that accounts for 1260 ORFs and thermodynamic information. Mol Syst Biol. 2007;3. doi:10.1038/ msb4100155.

36. Oliveira AP, Nielsen J, Förster J. Modeling Lactococcus lactis using a genome-scale flux model. BMC Microbiol. 2005;5:39.

37. Benedict MN, Gonnerman MC, Metcalf WW, Price ND. Genome-scale metabolic reconstruction and hypothesis testing in the methanogenic archaeon Methanosarcina acetivorans C2A. J Bacteriol. 2012;194:855-65. 